\title{
The potential of the educational environment of the military educational organization of higher education in the development of the intelligence of the future officer
}

\author{
P.Y. Naumov ${ }^{1 *}, N . B$. Karabuschenko ${ }^{2}$, and V.M. Bolshakova ${ }^{3}$ \\ ${ }^{1}$ FGKUZ «Center for military medical examination of the troops of the National Guard of the \\ Russian Federation», Moscow, Russia \\ ${ }^{2}$ Peoples ' Friendship University of Russia, Moscow, Russia \\ ${ }^{3}$ Russian Academy of National Economy and Public Administration under the President of the \\ Russian, Nizhny Novgorod, Russia
}

\begin{abstract}
During the developing of the officer's intelligence as a subjective personal education that characterizes his personality, it is not enough to identify the means and methods of such development, it is necessary to reveal the laws of his real existence and functioning of the components, to establish how this development is embedded in pedagogical activity and what conditions affect the change in its dynamics. It is possible by assessing the educational environment's potential of the military educational organization of higher education in the development of the intelligence of the future officer, by identifying the objective and subjective conditions of this environment and understanding the opportunities for teachers.
\end{abstract}

\section{A problem statement}

"Who should love peace, if not someone who can suffer from war? In whom should the fear of God be alive, if not in one who is daily exposed to innumerable dangers and most of all needs the help of the Most High? Thanks to this necessity, which was well understood by the legislators of empires and generals, the life of a soldier was glorified by other citizens, who tried in every possible way to follow and imitate it».

Nicollo Machiavelli, «The Art of War» [1].

«The commander must have wisdom, honesty, goodwill, courage and exactingness», «A skilled commander, free from the constant control of commanders, brings victory».

Sun Tzu, The Art of War [2].

Modern education, the programs of which are realized in educational organizations of various types (including military educational organizations of higher education), is aimed not only at training professional personnel who are able to perform a certain amount of

\footnotetext{
* Corresponding author: prof-ped.gpa@mail.ru
} 
tasks based on the received qualifications, but also at the harmonious development of the individual, the formation of values, beliefs and moral attitudes.

Education is an important institution of socialization and culturalization, designed to form and (or) instill individually and socially significant personality qualities. The value of education is that it participates in the creation and preservation of common values, without which a solidary, sustainable existence of society is impossible. The value of education is shown in the fact that it makes society qualitatively different in the following indicators: the composition of integrating components; the society of educated people provides a higher standard of living for its citizens; the society of educated people is conflictless.

In a military university, it is necessary not only to teach the future officer the basics of military sciences, to form general cultural, professional and special competencies in accordance with the federal state educational standards of higher education and qualification requirements, as well as the volume of the military accounting specialty being mastered, but also to form the personality of the future officer, and in its structure-a special type of ideological attitudes and abilities for skillful and conscientious preparation for the armed defense of the country, participation in its armed defense, and, if necessary, performing tasks in combat conditions, including at risk to health and life.

The nature of intelligence lies not in the possession of a certain amount of knowledge, the level of education, not in social origin and position. Its nature lies in the fact that in the course of these processes, the subject (the future officer) is embedded in the activities of the military intelligentsia and attached to its value-semantic guidelines. The main criterion for the subjectivity of an intellectual will not be the presence of a certain amount of knowledge that characterizes him as a person with appropriate training, not a document of education that characterizes the mastery of a certain educational program, but the level of his upbringing on the basis of education or the level of a formed system of values. The introduction to the system of values of intelligence occurs in the real joint activity of the teacher and the cadet, which does not imply a rigid administrative and power domination, but the relationship between the masters who have already reached the top, and the shift they bring up. If the pedagogical process turns «face» to its product-the future officer - and will properly stimulate independence, responsibility, discipline, awareness of the totality of their future social functions, it is possible for the individual to «enter» the social role that society has assigned to the officers.

The problems of the formation and development of intelligence in the conditions of higher education in the social and humanitarian knowledge are described by [2-17, etc.].

The solution of such a complex educational task contains two sections - external and internal. External includes a set of approaches with the use of appropriate pedagogical methods, tools and techniques to create, maintain and implement in practice certain organizational and psychological and pedagogical conditions that contribute to the development of the future officer's personality. The internal cross-section includes those qualities of the officer's personality that need to be formed, educated or developed in order for the officer not only to be able to defend the Motherland, but also to have a value attitude to this protection, and, consequently, to be able to organize his activities for this purpose. An integrative function in the unification of value orientations for serving the Motherland has a special, specific education, which is formed in the structure of the subjectivity of the future officer and which is called intelligence. It is its presence that allows, on the one hand, carrying the image and system of values of an officer through life, on the other hand, without hesitation, to begin to defend the Motherland at any time, in any conditions and in any situation.

Only intelligence allows you to realize the meaning $f$ life and purpose of the officer's activity - the protection of the country and its citizens from any forms of aggression, crime, terrorism and other offenses. At first, intelligence gives the officer the ability to make a 
special form of existential assessment-to relate each professional task to a life-meaning problem, based on the results of which it can be argued that the officer did not work, but served the Motherland and his people. At second, it allows the officer to possess a specific form of psychological experiences focused on the preservation and protection (including armed) of the Russian Federation and its citizens.

Many authors characterize the modern existence of pedagogical science with crisis tendencies in the field of education of the younger generation, since the performance of educational functions by educational organizations in the current conditions is not so effective. Such a situation has a number of objective and subjective reasons, but with the development of information and telecommunications technologies, such a complex task cannot be solved only by the efforts of the teaching staff of an educational organization.

In a military university, educational efforts in relation to the formation of a system of values (including intelligence) of a future officer will be much more effective in connection with the following:

a citizen enrolled in a military university begins to perform military service, acquires the status of a serviceman, is appointed to a military position, and is assigned a military rank;

in military universities, the traditional system of training and education of military personnel is preserved - it is being modernized and focused on the introduction of modern educational technologies, advanced pedagogical methods and techniques, but its organization remains almost unchanged;

- the access of cadets to the information and telecommunications network «Internet» is restricted by law, the cadet can access it only for a certain time and mainly for educational purposes;

the organization of the educational process is purposeful and complex, since educational functions are assigned to all categories of officials (the command of a military university, the teaching staff, management officers, unit commanders, junior commanders from among cadets, curators of cadet units);

during the education at a military university, the context of the real future professional and daily activities of the National Guard troops is created (modeled), cadets get used to the conditions and difficulties of service and everyday life of a soldier;

- a large number of academic subjects and classes are conducted with weapons, military and special equipment, working out practical tasks and standards, which allows the cadet to psychologically master the content and specifics of future professional tasks;

- a lot of official person among the teaching staff of the military university have experience of participating in combat operations and actually performing the tasks assigned to the armed forces.

However, the above features convey the general context of the educational, training and developing potential of a military university, but it alone cannot satisfy us. In our opinion, it is necessary to identify what conditions the educational environment of a military university has in the development of the intelligence of future officers, what specific functions it performs, through what negative and positive factors it affects. Thus, the study of the potential of the educational environment of a military university in the development of the intelligence of future officers is logically carried out through the solution of certain interrelated problems.

Following this logic, we note that the educational environment of a military university in the development of the intelligence of future officers has a complex of intellectualdeveloping, value-oriented, communicative-activity and subject-creative capabilities, using which it is really effective and effective to solve the problems of forming intelligence, both on the part of the teaching staff and the trainees themselves. 
Considering the functional side of the question, we relied on the research of P.K. Anokhin [1] on the theory of functional systems, and came to the conclusion that the educational environment of a military university in the development of the intelligence of future officers performs the following external (motivational-stimulating, environmental, security, implementation, regulatory-managerial, content, explanatory, value-oriented, emotional-adaptive) and internal (generating, subject-content, value-oriented, emotionalvolitional) functions.

During the researching of psychological and pedagogical foundations of the development of the intelligence of future officers, we identified and implemented the following psychological conditions: 1) achieving an understanding of the specific lifestyle of the subject, focusing on his professional and personal well-being; 2) activation of reflection (self-reflection) against the background of greater involvement in the social environment; 3) psychological support for the adoption of the social role of an officer and the adoption of an appropriate social « mask»; 4) strengthening of social interest in professional activity, with the aim of its development into a value attitude; 5) elimination of the situation of rejection from the military team, active inclusion of the cadet in the general social activities and behavior.

Also, the conditions in which the development of the future officer's intelligence takes place include: external and internal; service; household; natural adaptation; physiological; moral and moral; psychological and other conditions.

\subsection{The objective of the work}

The authors chose a systematic approach, as the main methodology of the study among the variety of methods of its use in social and humanitarian cognition. The main scientific results of the study are the author's view of the potential of the educational environment of a military university in the development of the intelligence of a future officer.

\section{Results of the research}

The main ways to improve the activities of military university officials in the development of the intelligence of future officers include pedagogical and methodological, methodological, technological, psychological, organizational, content-cognitive.

Researching these issues by analyzing the scientific literature and studying the essence and specifics of the pedagogical process in a military university, we can make a scientifically based conclusion that the educational environment of a military university in the development of the intelligence of a future officer has the following types of potential, which together contribute to the development of the intelligence of a future officer: cognitive-intellectual; ideological-axiological; sign-contextual; cultural-environmental; adaptation-orientation; emotional-volitional; developing; content-essential; socio-relay; communicative-activity; creative-implementation.

In the empirical part of research, the following psych diagnostic methods were used:

- R. Amthauer's test of the structure of intelligence - to diagnose the level of development of intellectual qualities;

- test of values of Sh. Schwartz (Value questionnaire of Sh. Schwartz);

- the CBS method (V.V. Sinyavsky, V.A. Fedoroshin) - to identify communicative and organizational inclinations.

The obtained results are presented in the form of summary tables, reflected in graphs and histograms. Group A was the experimental group, and group B was the control group (Table 1). 
Table 1. Analysis of the structure of intelligence.

\begin{tabular}{|c|c|c|c|c|c|c|c|}
\hline \multirow{2}{*}{ Scale } & \multicolumn{3}{|c|}{ Group A $(n=102)$} & \multicolumn{3}{|c|}{ Group B $(n=108)$} & \multirow{2}{*}{ t-Stud } \\
\hline & M & $\mathbf{m}$ & $\delta$ & M & $\mathbf{m}$ & $\delta$ & \\
\hline $\begin{array}{l}\text { Supplement suggestions (or } \\
\text { awareness (IN)) }\end{array}$ & 12.35 & 0.32 & 3.31 & 12.06 & 0.33 & 3.48 & 0.634 \\
\hline $\begin{array}{l}\text { Exclusion of a word (or } \\
\text { exclusion of excess (EL)) }\end{array}$ & 10.76 & 0.30 & 3.03 & 10.04 & 0.28 & 3.01 & 1.743 \\
\hline $\begin{array}{l}\text { Analogies (or finding } \\
\text { analogies }(A N))\end{array}$ & 9.81 & 0.26 & 2.61 & 9.87 & 0.29 & 2.97 & 0.147 \\
\hline 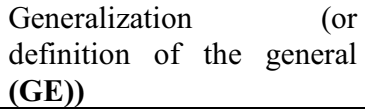 & 12.36 & 0.51 & 5.13 & 13.17 & 0.48 & 5.02 & 1.147 \\
\hline Arithmetic tasks (AR)) & 10.66 & 0.31 & 3.11 & 10.07 & 0.31 & 3.27 & 1.321 \\
\hline Numerical series $(N U))$ & 9.75 & 0.31 & 3.08 & 9.56 & 0.29 & 3.05 & 0.425 \\
\hline Space generalization $(P L))$ & 8.16 & 0.42 & 4.24 & 7.35 & 0.46 & 4.77 & 1.293 \\
\hline Space imagination (SP) & 8.49 & 0.37 & 3.73 & 7.95 & 0.36 & 3.72 & 1.041 \\
\hline Memory (ME)) & 11.66 & 0.53 & 5.34 & 10.79 & 0.53 & 5.52 & 1.160 \\
\hline
\end{tabular}

At the first stage of the study, the respondents of the experimental and control groups have similar indicators for sub-tests of intelligence, significant differences between the groups were not found. The development of their intelligence is characterized by an average level (Table 2).

Table 2. Analysis of the study of value orientations.

\begin{tabular}{|l|c|c|c|c|c|c|c|}
\hline \multirow{2}{*}{ Scale } & \multicolumn{3}{|c|}{ Group A (n= 102) } & \multicolumn{3}{c|}{ Group B (n= 108) } & \multirow{2}{*}{ t-Stud } \\
\cline { 2 - 8 } & $\mathbf{M}$ & $\mathbf{~ m}$ & $\boldsymbol{\delta}$ & $\mathbf{M}$ & $\mathbf{m}$ & $\boldsymbol{\delta}$ & ( \\
\hline Comfort & 3.77 & 0.20 & 2.02 & 3.87 & 0.53 & 1.97 & 0.347 \\
\hline Traditions & 4.11 & 0.23 & 2.29 & 4.33 & 0.19 & 2.07 & 0.748 \\
\hline Kindness & 4.06 & 0.18 & 1.83 & 3.99 & 0.19 & 1.78 & 0.272 \\
\hline Universalism & 4.26 & 0.18 & 1.85 & 4.17 & 0.17 & 1.83 & 0.385 \\
\hline Independence & 4.14 & 0.22 & 2.19 & 3.94 & 0.18 & 2.11 & 0.648 \\
\hline Stimulation & 4.47 & 0.21 & 2.14 & 4.55 & 0.20 & 2.00 & 0.263 \\
\hline Hedonism & 5.18 & 0.19 & 1.99 & 5.34 & 0.19 & 1.84 & 0.626 \\
\hline Achievement & 4.22 & 0.19 & 1.92 & 4.37 & 0.18 & 1.84 & 0.594 \\
\hline Power & 5.44 & 0.19 & 1.89 & 5.58 & 0.18 & 1.81 & 0.556 \\
\hline Safety & 3.73 & 0.17 & 1.69 & 3.84 & 0.15 & 1.63 & 0.509 \\
\hline Noty
\end{tabular}

Note: $\mathrm{M}$ is the arithmetic mean; $\mathrm{m}$ is the error of the mean; $\delta$ is the standard square deviation; $\mathrm{t}$ is the Student's test. The differences were significant at $\mathrm{p}<0.05 \mathrm{t}-\mathrm{cr}=1.972 ; \mathrm{p}<0.01 \mathrm{t}-\mathrm{cr}=2.601$; $\mathrm{p}<0.001 \mathrm{t}-\mathrm{cr}=3.340$.

According to the presented data, it can be noted that there are no significant differences in the value orientations of the respondents of the experimental and control groups (Table 3).

The development of communication and organizational skills in the respondents of the experimental and control groups is at an average level with a tendency to low indicators. No significant differences were found at the first stage either. 
Table 3. Analysis of the study of communicative and organizational inclinations.

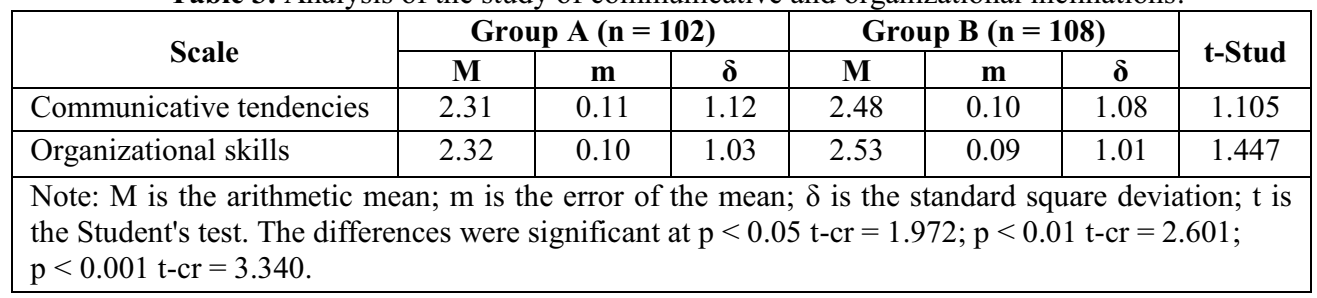

At the next stage of research, a formative experiment was conducted. Upon completion of the work, a control psychodiagnostic examination was conducted with the help of similar methods with the respondents of the experimental and control groups. The results obtained are presented in the form of summary tables, reflected in graphs and histograms (Table 4).

Table 4. Analysis of the structure of intelligence.

\begin{tabular}{|l|c|c|c|c|c|c|c|}
\hline \multirow{2}{*}{ Scale } & \multicolumn{3}{|c|}{ Group A (n= 102) } & \multicolumn{3}{c|}{ Group B (n= 108) } & \multirow{2}{*}{ t-Stud } \\
\cline { 2 - 8 } & $\mathbf{M}$ & $\mathbf{~ m}$ & $\boldsymbol{\delta}$ & $\mathbf{M}$ & $\mathbf{m}$ & $\boldsymbol{\delta}$ & \\
\hline Adding suggestions (IN)) & 14.24 & 0.33 & 3.48 & 13.04 & 0.29 & 2.99 & $\mathbf{2 . 6 7 8}$ \\
\hline Excepting a word (EL)) & 12.68 & 0.29 & 3.01 & 11.21 & 0.28 & 2.80 & $\mathbf{3 . 6 6 3}$ \\
\hline Analogies $(A N))$ & 11.03 & 0.29 & 2.97 & 10.03 & 0.25 & 2.57 & $\mathbf{2 . 6 1 5}$ \\
\hline generalization (GE)) & 12.03 & 0.48 & 5.01 & 11.84 & 0.54 & 5.48 & 0.258 \\
\hline Arithmetic tasks $(A R))$ & 12.08 & 0.32 & 3.27 & 11.09 & 0.35 & 3.51 & $\mathbf{2 . 1 0 6}$ \\
\hline Numerical series $(N U))$ & 10.20 & 0.29 & 3.05 & 9.26 & 0.32 & 3.19 & $\mathbf{2 . 1 6 6}$ \\
\hline Space generalization $(P L))$ & 10.10 & 0.46 & 4.77 & 8.83 & 0.41 & 4.15 & $\mathbf{2 . 0 5 2}$ \\
\hline Space imagination (SP) & 9.68 & 0.36 & 3.72 & 9.43 & 0.44 & 4.44 & 0.429 \\
\hline Memory (ME)) & 16.02 & 0.53 & 5.52 & 13.07 & 0.54 & 5.49 & $\mathbf{3 . 8 8 2}$ \\
\hline Ne: & & & & & & \\
\hline
\end{tabular}

Note: $\mathrm{M}$ is the arithmetic mean; $\mathrm{m}$ is the error of the mean; $\delta$ is the standard square deviation; $\mathrm{t}$ is the Student's test. The differences were significant at $\mathrm{p}<0.05 \mathrm{t}-\mathrm{cr}=1.972 ; \mathrm{p}<0.01 \mathrm{t}-\mathrm{cr}=2.601$; $\mathrm{p}<0.001 \mathrm{t}-\mathrm{cr}=3.340$.

After conducting the formative experiment, the intellectual development indicators of the respondents in the experimental group significantly increased in most of the subtests.

The respondents of the experimental group significantly increased their general awareness, sense of language and inductive speech thinking (the «exclusion of excess» subtest), and combinatorial abilities.

The respondents of the experimental group at the second stage have significantly higher indicators for mathematical subtests, which indicate the development of the ability to quickly solve formalized problems, the desire for ordering of cases and tasks. Significantly increased the indicators of mnemic abilities (subtest «memory») (Table 5).

After conducting the formative experiment, the respondents of the experimental group significantly increased the value of traditions, independence, the value of achievements, and security (Table 6). 
Table 5. Analysis of the study of value orientations.

\begin{tabular}{|c|c|c|c|c|c|c|c|}
\hline \multirow{2}{*}{ Scale } & \multicolumn{3}{|c|}{ Group A $(n=102)$} & \multicolumn{3}{|c|}{ Group B $(n=108)$} & \multirow{2}{*}{ t-Stud } \\
\hline & M & m & $\delta$ & M & m & $\delta$ & \\
\hline Comfort & 3.98 & 0.19 & 1.97 & 3.75 & 0.20 & 2.00 & 0.804 \\
\hline Traditional & 4.98 & 0.20 & 2.07 & 4.10 & 0.24 & 2.38 & 2.857 \\
\hline Kindness & 4.21 & 0.17 & 1.78 & 4.10 & 0.19 & 1.91 & 0.438 \\
\hline Universalism & 4.59 & 0.18 & 1.83 & 4.25 & 0.18 & 1.83 & 1.310 \\
\hline Independence & 5.23 & 0.20 & 2.11 & 4.15 & 0.22 & 2.25 & 3.591 \\
\hline Stimulation & 4.55 & 0.19 & 2.00 & 4.53 & 0.21 & 2.15 & 0.057 \\
\hline Hedonism & 5.23 & 0.18 & 1.84 & 5.15 & 0.20 & 2.06 & 0.310 \\
\hline Achievement & 5.08 & 0.18 & 1.84 & 4.09 & 0.19 & 1.8 & 3.841 \\
\hline Power & 5.79 & 0.17 & 1.80 & 5.49 & 0.19 & 1.91 & 1.161 \\
\hline Safety & 4.32 & 0.16 & 1.63 & 3.66 & 0.16 & 1.62 & 2.949 \\
\hline
\end{tabular}

Note: $\mathrm{M}$ is the arithmetic mean; $\mathrm{m}$ is the error of the mean; $\delta$ is the standard square deviation; $\mathrm{t}$ is the Student's test. The differences were significant at $\mathrm{p}<0.05 \mathrm{t}-\mathrm{cr}=1.972 ; \mathrm{p}<0.01 \mathrm{t}-\mathrm{cr}=2.601$; $\mathrm{p}<0.001 \mathrm{t}-\mathrm{cr}=3.340$.

Table 6. Analysis of researching of communicative and organizational inclinations.

\begin{tabular}{|c|c|c|c|c|c|c|c|}
\hline \multirow[t]{2}{*}{ Scale } & \multicolumn{3}{|c|}{ Group A $(n=102)$} & \multicolumn{3}{|c|}{ Group B $(n=108)$} & \multirow[t]{2}{*}{ t-Stud } \\
\hline & M & $\mathbf{m}$ & $\delta$ & M & $\mathbf{m}$ & $\delta$ & \\
\hline Communicative skills & 3.05 & 0.10 & 1.08 & 2.35 & 0.11 & 1.09 & 4.636 \\
\hline Organizational skills & 2.68 & 0.10 & 1.01 & 2.34 & 0.10 & 1.01 & 2.359 \\
\hline \multicolumn{8}{|c|}{$\begin{array}{l}\text { Note: } \mathrm{M} \text { is the arithmetic mean; } \mathrm{m} \text { is the error of the mean; } \delta \text { is the standard square deviation; } \mathrm{t} \text { is } \\
\text { the Student's test. The differences were significant at } \mathrm{p}<0.05 \mathrm{t}-\mathrm{cr}=1.972 ; \mathrm{p}<0.01 \mathrm{t}-\mathrm{cr}=2.601 ; \\
\mathrm{p}<0.001 \mathrm{t}-\mathrm{cr}=3.340 \text {. }\end{array}$} \\
\hline
\end{tabular}

As can be seen in the tables, after conducting the formative experiment, the respondents of the experimental group were diagnosed with a significantly higher level of communicative and organizational inclinations. This dynamic occurred due to the expansion of the range of communication and organizational skills.

Thus, the conducted study showed the effectiveness of the formative experiment for most of the diagnosed indicators.

One of the current proposals for improving the work in the field of education of cadets and the formation of their value orientations (including the values of intelligence) is to optimize the working time of the teaching staff and release a certain budget for solving the tasks of developing the cadet's personality. An important way in this case is to reduce the number of hours or completely reduce them for commanding, combat and moral and psychological training of military personnel from among the teaching staff who have academic degrees (titles) and practical experience in the troops (including experience of participation in combat operations) and partially replace it with independent work. The desirability of this cancellation is due to the fact that such military personnel as highly qualified personnel have the required level of education, are able to learn more deeply and broadcast the taught subject (discipline), and if necessary, their official use, for example, for solving combat tasks, short-term courses of additional retraining/advanced training will be enough. Such actions will significantly relieve the most trained teaching staff and free up the time budget for more effective and efficient implementation of training and education of cadets. 


\section{Conclusions}

In conclusion, I would like to note: no matter how the educational process is organized in a military university, no matter how modern educational technologies are, no matter how the technological way of using weapons and military equipment changes, no matter how modern the automatic machines and simulators used in training cadets in military skills, the most important role in the formation of the values of the future officer's personality, his general culture, his intelligence is performed by the personal example of existing officers who educate, train, organize service and daily life, which simply surround him. It is their actions, their social relays, the structure and direction of their activities, their beliefs and ideological attitudes, their values that are transmitted to the cadet through a social program called «military service» through the pedagogical process through emotional and intellectual interaction. Exactly looking at their commanders and teachers that the cadet forms his own social experience, learns the manners of behavior with commanders (superiors) and subordinates, learns to solve real service and educational tasks, to appreciate military traditions and general military regulations. Exactly through the personal example of tutors that the cadet learns and experiences the very process of becoming a future officer in him, his knowledge, values, skills and skills. Due to features of the activity, endurance, will, pedagogical tact, education of the teaching staff, unit commanders, officers of the management and command of the military university, depend on how quickly and how deeply the cadet «tries on» the social role of a Defender of the Motherland, an officer, an intelligent.

\section{References}

1. P.K. Anokhin, Key questions of the theory of functional systems, 196 (1980)

2. M.S. Kagan, Reproduction of the Russian intelligentsia as a pedagogical problem, 130-133 (2000)

3. M.S. Kagan, City of Petrov in the history of Russian culture, 499 (2018)

4. L.A. Keleman, The concept of «intelligence» in the Russian spiritual tradition, Bulletin of the Stavropol State University, 36, 70-78 (2004)

5. S.V. Kovaleva, Formation of intelligence: ontological aspect, Intelligentsia and the World, 4, 59-76 (2011)

6. I.S. Kon, Reflections on the American intelligentsia, New World, 1, 173-197 (1968)

7. E.N. Larionova, The nature and essence of the concept of intelligence, Analytics of cultural studies, 1(28), 30-34 (2014)

8. D.S. Likhachev, Selected Works on Russian and World Culture, 416 (2006)

9. A.F. Losev, On intelligence, Credo new, 1 (2006)

10. E.A. Martynova, Typologization and axiological foundations of intelligence, Psychological and pedagogical problems of human security and society, 4(29), 8-11 (2015)

11. P.Y. Naumov, F.V. Povshednaya, Psychological and pedagogical conditions for the formation of value attitudes towards intelligence among future officers in the environment of the military educational organization of higher education, Bulletin of Minin University, 8(1), 9 (2020)

12. P.Yu. Naumov, F.V. Povshednaya, The psychological nature of the officer's intelligence, Bulletin of the Minin University, 8(2), 12 (2020) 
13. A.V. Popov, Genesis, formation and development of the system of values of the military intelligentsia of Russia, 43 (2012)

14. A.V. Sokolov, Formula of intelligence, Questions of Philosophy, 5, 57-67 (2005)

15. A.V. Sokolov, Intellectuals and intellectuals in Russian history, 344 (2007)

16. V.V. Tepikin, Crystallization of the intelligentsia, 129 (2011)

17. V.V. Tepikin, Relations between the artistic intelligentsia and the authorities of the 60 s of the twentieth century in national historiography (stages 1 and 2), Man in the social world: interdisciplinary scientific and practical bulletin of the Research Institute of Social Problems of the Russian Academy of Natural Sciences, 1, 80-81 (2006)

18. A.A. Trufanov, Foundations of the theory of intelligence, 271 (2002)

19. S.G. Chukin, Education as a value, Bulletin of the St. Petersburg Military Institute of National Guard Troops, 1(2), 63-70 (2018)

20. Wu Tzu (Sun Tzu), The Art of War, 480 (2012)

21. Machiavelli, Nicollo. Sovereign, The Art of War, 448 (2020) 